\title{
ON THE LOCATION OF EIGENVALUES OF MATRIX POLYNOMIALS
}

\author{
CÔNG-TRÌnh LÊ, THI-HoA-BInH Du AND TRAN-DUC NGUYEN
}

\begin{abstract}
A number $\lambda \in \mathbb{C}$ is called an eigenvalue of the matrix polynomial $P(z)$ if there exists a nonzero vector $x \in \mathbb{C}^{n}$ such that $P(\lambda) x=0$. Note that each finite eigenvalue of $P(z)$ is a zero of the characteristic polynomial $\operatorname{det}(P(z))$. In this paper we establish some (upper and lower) bounds for eigenvalues of matrix polynomials based on the norm of their coefficient matrices and compare these bounds to those given by N. J. Higham and F. Tisseur [8], J. Maroulas and P. Psarrakos [12].
\end{abstract}

Mathematics subject classification (2010): 15A18, 15A42, 65F15.

Keywords and phrases: Matrix polynomial, $\lambda$-matrix, polynomial eigenvalue problem.

\section{REFERENCES}

[1] P. Borwein And T. ERdÈLyi, Polynomials and Polynomial Inequalities, Springer-Verlag, New York, 1995.

[2] M. Dehmer, On the location of zeros of complex polynomials, J. Inequal. Pure Appl. Math. 7,1 (2006), 1-13.

[3] B. Datt And N. K. Govil, On the location of the zeros of a polynomial, J. Approx. Theory 24, (1978), 78-82.

[4] G. DiRR AND H. K. Wimmer, An Eneström-Kakeya theorem for hermitian polynomial matrices, IEEE Trans. Automat. Control 52, (2007), 2151-2153.

[5] R. A. Frazer, W. J. Duncan And A. R. Collar, Elementary matrices, 2nd ed., Cambridge Univ. Press, London and New York, 1955.

[6] I. Gohberg, P. Lancaster And L. Rodman, Matrix Polynomials, Academic Press, New York, 1982.

[7] S. Hamarling, C. J. MunRo And F. Tisseur, An algorithm for the complete solution of quadratic eigenvalue problems, ACM Trans. Math. Softw. 39, 3 (2013).

[8] N. J. Higham And F. Tisseur, Bounds for eigenvalues of Matrix Polynomials, Linear Algebra and Its Applications 358, (2003), 5-22.

[9] A. Joyal, G. Labelle And Q. I. Rahman, On the location of zeros of polynomials, Cand. Math. Bull. 10, (1967), 53-63.

[10] P. LAnCASTER, Lambda-matrices and vibrating systems, Pergamon, Oxford, 1966.

[11] M. MARden, Geometry of polynomials, Mathematical Surveys. Amer. Math. Soc., Rhode Island, 3, 1966.

[12] J. MAROULAS AND P. PSARRAKOS, The boundary of numerical range of matrix polynomials, Linear Algebra Appl. 267 (1997), 101-111.

[13] G. V. Milovanović AND TH. M. RAssias, Inequalities for polynomial zeros, In: Survey on Classical Inequalities (Th. M. Rassias, ed.), Mathematics and Its Applications, Vol. 517, pp. 165-202, Kluwer, Dordrecht, 2000.

[14] V. Mehrmann And D. Watkins, Polynomial eigenvalue problems with Hamiltonian structure, Electron. Trans. Numer. Anal. 13, (2002), 106-118.

[15] G. Singh And W. M. Shah, On the Location of Zeros of Polynomials, Amer. J. Comp. Math. 1, 1 (2011), 1-10.

[16] V. Simoncini And F. Perotti, On the Numerical Solution of $\left(\lambda^{2} A+\lambda B+C\right) x=b$ and Application to Structural Dynamics, SIAM J. Sci. Comput. 23,6 (2006), 1875-1897. 
[17] J. Swoboda AND H. K. Wimmer, Spectraloid operator polynomials, the approximate numerical range and an Eneström-Kakeya theorem in Hilbert space, Studia Math. 198 (2010), 279-300.

[18] F. TisSEUR AND N. J. HighaM, Structured pseudospectra for polynomial eigenvalue problems, with applications, SIAM Journal On Matrix Analysis And Applications 23, 1(2001), 187-208.

[19] F. Tisseur And K. Meerbergen, The quadratic eigenvalue problem, SIAM Review, 43, 2(2001), 235-286.

[20] L. ZENG AND Y. SU, A backward stable algorithm for quadratic eigenvalue problems, SIAM J. Matrix Anal. Appl. 35, 2(2014), 499-516. 